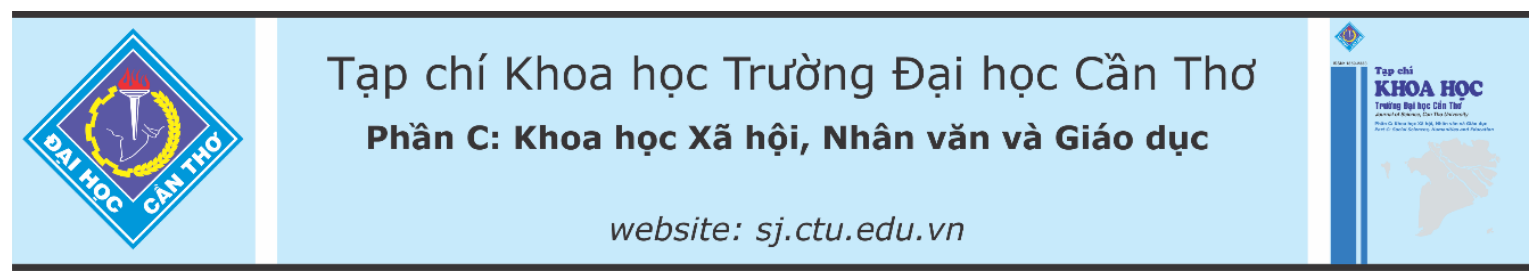

DOI:10.22144/ctu.jvn.2021.025

\title{
MOTIF NGHỆ THUẠT TRONG TÁC PHẨM HÓA THÂN CỦA FRANZ KAFKA
}

\author{
Trần Vũ Anh và Phạm Tuấn Anh* \\ Khoa Su phạm, Trường Đại học Cần Tho \\ *Nguời chịu trách nhiệm về bài viết: Phạm Tuấn Anh (email: ptanh@ctu.edu.vn)
}

\section{Thông tin chung:}

Ngày nhận bài: 23/11/2020

Ngày nhận bài sưa: 26/01/2021

Ngày duyệt đăng: 27/02/2021

Title:

Artistic motif used in the Metamorphosis by Franz Kafka

\section{Tù khóa:}

Motif nghệ thuật, văn học hiện đại, hậu hiện đại, Hóa thân, Franz Kafka

Keywords:

Artistic motifs, modern literature, postmodern, The Metamorphosis, Franz Kafka.

\begin{abstract}
Franz Kafka is a Jewish writer composing mainly in German. Up to now, many Kafka's works have been selected, translated and introduced in Vietnam: The Metamorphosis, the Castle, the Trial, Amerika, Letter to the father, etc. Kafka's works restore a cracked and broken world with full of skepticism and cognitive distrust. The Metamorphosis is a typical work of Kafka's composing legacy. In The Metamorphosis, Kafka cleverly interwoven and assembled many artistic motifs to convey the value of the work, stimulate the readers' thinking of exploration and discovery. In this study, we focus on the interpretation of the metamorphosis motif - the motif that plays an important role in conveying inexplicable problems in modern life. From there, we analyze Kafka's success and contribution to the world literature.
\end{abstract}

\section{TÓM TÁT}

Franz Kafka là nhà văn gốc Do Thái, sáng tác chủ yếu bằng tiếng Đức. Đến nay, nhiều tác phẩm của Kafka được tuyển dịch và giới thiệu ở Việt Nam: Hóa thân, Lâu đài, Vu án, Nước Mỹ, Thu gửi bố... Tác phẩm của Kafka phuc dụng một thế giới rạn nưt, võ̃ vun, đầy hoài nghi và bất tín nhận thức. Hóa thân là tác phẩm tiêu biểu trong di sản sáng tác của Kafka. Trong Hóa thân, Kafka khéo léo đan cài, ráp nối nhiều motif nghệ thuật để truyền tải giá trị tác phẩm, kích thich tu duy tìm tòi, khám phá của độc giả. Trong nghiên cứu này, chúng tôi tập trung kiến giải motif hóa thân motif đóng vai trò quan trọng trong viẹc truyền tải các vấn đề bất khả giải trong đời sống hiện đại. Tù đó, chúng tôi phân tích sư thành công và đóng góp của Kafka trong nền văn học thế giới.

\section{1. ĐặT VẤN ĐỀ}

Franz Kafka (1883 - 1924) là nhà văn gốc Do Thái, sáng tác chủ yếu bằng tiếng Đức. Sinh thời, Kafka viết văn bằng nỗi niềm day dứt đối với xã hội đầy xáo động và bất ổn. Di sản sáng tác của Kafka để lại không nhiều nhưng những trang viết ấy có ý nghĩa quan trọng đối với tiến trình văn học nhân loại. Đến nay, nhiều tác phẩm của Kafka được tuyển dịch và giới thiệu ở Việt Nam: Hóa thân, Lâu đài, Vu án, Nước Mỹ, Thu gửi bố... Các tác phẩm của
Kafka phục dựng một thế giới rạn nứt, vỡ vụn, đầy hoài nghi và bất tín nhận thức. Dưới ngòi bút của "người viết Kinh thánh hiện đại" (Lê Huy Bắc, 2019, tr 13), hiện thực thậm phồn, đa chiều kích được tái hiện khéo léo và tinh vi. Kafka mang đến cho người đọc một cái nhìn nghiệt ngã, đầy trúc trắc về hiện thực và con người trong kỷ nguyên kỹ trị.

Hóa thân là tác phẩm tiêu biểu cho kĩ thuật viết văn của Kafka. Nhà văn đan cài, ráp nối nhiều motif nghệ thuật để truyền tải giá trị tác phẩm, tiêu biểu 
như motif "giấc mơ - bừng ngộ", "xung đột cha và con", "hóa thân",... Nghiên cứu motif nghệ thuật trong tác phẩm Hóa thân là một trong những hướng tiếp cận giúp khám phá giá trị nội dung và nghệ thuật của tác phẩm. Trong nghiên cứu này, chúng tôi không có tham vọng đề cập đến tất cả các motif nghệ thuật được đan cài trong tác phẩm, mà chỉ tập trung kiến giải motif hóa thân - motif đóng vai trò quan trọng trong việc truyền tải các vấn đề bất khả giải trong đời sống hiện đại.

\section{NỘI DUNG}

Franz Kafka là thiên tài nghịch dị, ngòi bút của ông như "thâu tóm trong nó gần như mọi linh hồn của thời đại” (Lê Huy Bắc, 2019, tr 15). Dựa trên "tính huyền ảo, mảnh vỡ, đa trị, hư vô hỗn độn và thái độ bất tín ngôn ngữ” (Lê Huy Bắc, 2013, tr 48), Lê Huy Bắc nhận định: “...ông "không cố chấp” và luôn cố "giải cấu trúc" nhiều thứ [...] Tác phẩm ông là "mẫu" cho nhiều trường phái nghiên cứu. Có thể có nhiều cách tiếp cận, và có thể có nhiều kết luận về ông mà cách nào cũng thỏa đáng." (Lê Huy Bắc, $2019, \operatorname{tr} 8)$. Kafka là một trong những nhà văn tiên phong khai sinh chủ nghĩa hiện đại trong văn xuôi thế kỷ XX, đồng thời là nhà văn có ảnh hưởng sâu rộng đến văn học hậu hiện đại thế kỷ XXI.

Bằng tài năng và cảm quan tinh tế, Franz Kafka khéo léo phản ánh hiện thực đời sống vào trong tác phẩm của mình. Đó là "hiện thực thậm phồn" (hyperreality) - "một kiểu hiện thực khác lạ, kiểu hiện thực đa chiều kích, có thể mở rộng đến bất kì nơi nào trí tưởng tượng của con người vươn đến" (Lê Huy Bắc, 2013, tr 39). Kafka nhấn mạnh sự trống vắng, phá sản tình thương, thiếu gắn kết giữa người với người trong xã hội hiện đại.

\subsection{Về khái niệm motif và motif hóa thân}

Motif là thuật ngữ chỉ "thành tố bền vững, vừa mang tính hình thức vừa mang tính nội dung của văn bản văn học; motif có thể được phân xuất từ trong một hoặc một số tác phẩm văn học của một nhà văn hoặc trong văn cảnh của toàn bộ sáng tác của nhà văn ấy, hoặc trong văn cảnh của một khuynh hướng văn học, một thời đại văn học nào đó" (Lại Nguyên Ân, 2003, tr 209). Trong Motif nghiên cúu truyện dân gian: lý thuyết và ứng dụng, La Mai Thi Gia đúc kết và dẫn ra nhiều quan điểm của các nhà nghiên cứu khi bàn về khái niệm motif. Theo đó, Veselovsky định nghĩa: "Motif là một công thức sơ khởi, một đơn vị trần thuật đơn giản nhất không thể chia cắt được" (La Mai Thi Gia, 2015, tr 66). Meletinsky nhận định: "Motif là hạt nhân của hành động” (La Mai Thi Gia, 2015, tr 66). Nhà phân tâm học Jung cho rằng: "Motif cũng như cổ mẫu là những hình ảnh, những biểu tượng, những hành động...đặc trưng được lặp đi lặp lại trong nhiều tác phẩm khác nhau" (La Mai Thi Gia, 2015, tr 107). Như vậy, có thể hiểu motif là thành tố hợp thành chỉnh thể tác phẩm văn học, được hiểu như một dạng "khuôn" trong sáng tác của cá nhân, một số tác giả hoặc của một giai đoạn văn học nào đó. Motif đóng vai trò quan trọng trong việc thể hiện chủ đề, cốt truyện của tác phẩm nghệ thuật, đồng thời bộc lộ cảm quan của nhà văn về hiện thực đời sống.

Motif có khởi nguồn từ nghiên cứu loại hình văn học dân gian. Nghiên cứu motif trong tác phẩm có ý nghĩa quan trọng trong việc lý giải nhận thức, quan niệm của con người về hiện thực đời sống. Về sau, motif dần trở thành hướng tiếp cận (đối tượng nghiên cứu) trong nghiên cứu của văn học viết, đặc biệt là nghiên cứu sáng tác của các nhà văn Âu - Mỹ có sử dụng phương thức sáng tác huyền thoại với cảm quan mới (có phần bi đát, hư vô) như Franz Kafka, Jame Joyce, William Faulkner,...

Từ nhan đề tiếng Anh Metamorphosis, các dịch giả ở Việt Nam chuyển dịch thành Hóa thân (hay Biến dạng). Nguyễn Lân (2000, tr 844) biểu đạt thuật ngữ trên bằng lối phân tích chiết tự: "Hóa thân (hóa: biến đổi; thân: mình) nói thần thánh biến hóa thân của mình theo quan niệm mê tín; biến đổi kì diệu". Motif hóa thân là một phương thức nghệ thuật tập hợp các "kiểu", "dạng" biến đổi của hình tượng nhân vật trong tác phẩm văn học, sự biến đổi này có thể làm thay đổi nhân vật về ngoại hình, tính cách, suy nghĩ; có ý nghĩa quan trọng trong việc cấu thành chỉnh thể tác phẩm.

\subsection{Diễn trình hóa thân của nhân vật}

Hóa thân là motif quen thuộc, phổ biến trong văn học các nước. Trong văn học truyền thống, diễn trình hóa thân của nhân vật thường xây dựng theo kiểu "Người - Vật - Người" hoặc "Vật - Người Vật" (Đặng Anh Đào, 1997, tr 647). Diễn trình Người - Vật - Người, tiêu biểu có thể kể đến nhân vật chàng trai thứ một trăm tìm đến cầu hôn cô công chúa trong truyện Con thỏ biển (Truyện cổ Grimm),

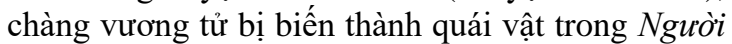
đẹp và quái vật của Villeneuve, mười một chàng hoàng tử bị hóa thành chim thiên nga trong $B \hat{a} y$ chim thiên nga của Andersen,... Diễn trình Vật - Nguời $V a ̣ ̂ t$ với chủ thể hóa thân chính là các con vật, chủ yếu là cáo, hồ ly xuất hiện nhiều trong Liêu trai chí dị của Bồ Tùng Linh hoặc trong truyện dân gian các nước,,.. . 
Trong Hóa thân, Kafka vẫn sử dụng công thức hóa thân, đội lốt nhưng theo cách riêng. Nhân vật chính Gregor Samsa từ Người hóa thân thành Vật $(B O)$ và cuối cùng tiến dần đến sự diệt vong - cái chết. Đặng Anh Đào (1997, tr 647) nhận định: “Chu kì hóa thân của Gregor Samsa trong Biến dạng đã khép kín, vô vọng: Người - Bọ - Cái chết" (. Trong văn học truyền thống, đặc biệt là truyện cổ tích, quan niệm "ở hiền gặp lành", "ác giả ác báo" được khẳng định, đề cao. Nhân vật được đặt trong tình thế bất khả kháng, buộc phải hóa thân, sau đó họ cố gắng quay trở về hình dạng ban đầu. Do vậy, diễn trình hóa thân của nhân vật thường theo chu kỳ khép kín, tuần hoàn, có tính nhân quả. Trong Hóa thân, diễn trình hóa thân của nhân vật không nhuốm màu cổ tích như văn học truyền thống, nhân vật bị biến dạng, nhanh chóng chấp nhận sự biến dạng và khước từ quay về hình dạng ban đầu. Lê Thanh Nga (2006, tr 176) nhận định: "Một mặt Kafka như một nhà văn hóa muốn lưu giữ những kí ức nhân loại trong sáng tác của mình, một mặt ông cũng tìm cách khước từ những ảnh hưởng của tư duy nguyên hợp, để tạo ra một bước ngoặt mới trong hình thức huyền thoại, khai sinh chủ nghĩa huyền thoại thế kỷ XX". Vận dụng motif hóa thân, Kafka có sự kế thừa, tiếp nối tư duy huyền thoại cổ xưa. Có điều, motif hóa thân trong tác phẩm của ông thể hiện dấu ấn riêng, bộc lộ cái nhìn có phần bi đát, đứt gãy về hiện thực đời sống. Rõ ràng, diễn trình hóa thân trong tác phẩm của Kafka không nhằm mục đích giải thích thế giới, củng cố, khẳng định niềm xác tín nào đó, mà trái lại, thể hiện sự đánh đổ, hoài nghi về một thế giới đầy rẫy nồi lo âu và phi lí.

Bằng giọng điệu trung tính khi trần thuật, Kafka dựng lại sự việc hóa thân của nhân vật Samsa một cách ngẫu nhiên, đột ngột. Samsa là nhân viên tiếp thị ở một hãng vải. Một buổi sáng tỉnh dậy, anh thấy mình đã biến thành con côn trùng khổng lồ. Thoạt đầu, Samsa lo lắng ngoại hình sẽ ảnh hưởng đến công việc mình. Thế rồi, anh thích nghi với hình hài con bọ: sử dụng chiếc lưng rắn chắc để xuống giường, dùng chuỗi âm thanh bị biến đổi trong khoang miệng để đáp lời người khác, di chuyển bằng những đôi chân kì quặc, dùng bộ hàm để mở cánh cửa phòng và ra khỏi phòng bằng cách $\mathrm{di}$ chuyển sát mặt đất của loài bọ,... Samsa dần thích nghi với lối sống mới. Anh ít giao tiếp với mọi người, thích chui rúc dưới gầm giường hoặc lẫn trốn ở một góc khuất nào đó. Anh thay đổi thói quen ăn uống và lối sống của bản thân cho phù hợp với lốt con bọ: ăn đồ ôi thiu và bò quanh tường. Trong hình hài con bọ, Samsa có thời gian suy ngẫm về bản thân mình, phát hiện nhiều điều thú vị trong cuộc sống mà trước kia, trong hình hài con người, anh không nghiệm ra. Samsa biến dạng về ngoại diện, điều này đồng nghĩa với việc anh bị tước bỏ khả năng lao động và kiếm tiền. Cha mẹ và cô em gái xem anh là con vật thừa thải trong nhà và rủ bỏ sự hiện diện của anh. Samsa rơi vào bi kịch tinh thần, và cuối cùng đi đến tận cùng của chuỗi biến dạng: cái chết. Samsa chết ở góc phòng, gia đình anh thở phào nhẹ nhõm. Rõ ràng, nhân vật bị biến dạng và nhanh chóng chấp nhận sự biến dạng như một điều tất yếu, tự nhiên. Diễn trình hóa thân của Samsa là một chuỗi biến đổi phức tạp cả về ngoại hình, nội quan, giọng nói, tập tính, thói quen lẫn suy nghĩ của nhân vật. Nhân vật ngày càng dấn sâu vào địa giới của một con bọ nhưng phần người vẫn được duy trì: khuôn mặt quái gở của Samsa trên tấm thân và hơn cả là những suy nghĩ, khát khao và ước vọng của anh vẫn còn hiện hữu trong hình hài con bọ. Sự dung hợp của hai yếu

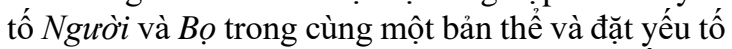
Người trước ngưỡng cửa của sự diệt vong là điều mà Kafka trăn trở, gợi mở và gửi gắm vào trong tác phẩm.

Diễn trình hóa thân ở Samsa phản ánh sự đổ vỡ niềm tin của con người trong kỷ nguyên hiện đại. Max Brod, khi nghiên cứu các tác phẩm của Kafka, đã đặt ra vấn đề về cảm quan đổ vỡ niềm tin của con người trong đời sống hiện đại. Samsa là hình tượng nhại hình ảnh của Đức Chúa trong huyền thoại. Bằng phương thức nhại lại huyền thoại về Đức Chúa cứu thế, hình tượng nhân vật Samsa được nâng tầm khái quát để tô đậm vết rạn về niềm tin của con người trong kỷ nguyên kỹ trị: "Chúa đã chết" (Nietzsche). Hành động cứu rỗi sinh linh của Đức Chúa ở khắp xứ Galilea được đặt đối sánh với nhiệm vụ cứu vớt đời sống vật chất của cả gia đình đang đè nặng trên vai Gregor Samsa: Đức Chúa thuyết giáo và chữa bệnh để cứu người thì Gregor Samsa cứu lấy một gia đình thoát khỏi hố sâu tuyệt vọng mà ông bố đã "ném" vào. Cũng vì thế mà họ bị trói buộc bởi nghĩa vụ và trách nhiệm. Bất hạnh lại ập đến những con người cứu rỗi: Đức Chúa bị đóng đinh trên cây thập tự giá vì sự phản bội của Judas Iscariot, còn Gregor Samsa chết đi cũng vì sự ghẻ lạnh của các thành viên trong gia đình. Sự thống khổ của cuộc hành quyết trên cây thập giá được mô tả lại chính bằng những nỗi đau về thể xác và tinh thần mà Samsa phải chịu đựng trong hình hài con bọ, thứ đã được cụ thể hóa bằng những lời chì chiết của gia đình và một quả táo thối rữa cắm chặt vào lưng Samsa. Kết cục, Đức Chúa tạ thế và được phục sinh với ý nghĩa mở ra một chiều hướng tồn tại mới để giải thoát con người khỏi đau khổ, còn đối với Samsa, anh lại bị đặt vào ngõ cụt của cái chết: chết 
trong nỗi cô đơn giữa đồng loại. Rõ ràng, cái chết của Samsa bộc lộ sự hoài nghi của con người đối với các giá trị trước đó, thứ đã từng tồn tại và được xem là chân lý. Bố mẹ và cô em gái của Samsa, từ khi họ có thể tự làm việc và kiếm tiền, đã cắt đứt mối liên hệ mang onn - trả ơn sẵn có trong gia đình. Samsa trở thành người thừa, là gánh nặng cần phải tống khứ và ruồng bỏ: "Từ đầu đến cuối, tâm tính của Gregor là của một con người nhưng anh dần biến thành côn trùng bởi ánh mắt của những người xung quanh" (Nguyễn Thị Mai Liên, 2019). Diễn trình hóa thân của Samsa đã đặt ra vấn đề suy ngẫm: đồng tiền với hình hài sắc lạnh như một nhát cắt chia cách mối quan hệ giữa người với người trong xã hội hiện đại.

Trong Hóa thân, tính phản huyền thoại (huyền thoại lộn trái) được thể khá rõ qua diễn trình hóa thân của nhân vật. Thủ pháp huyền thoại lộn trái bao hàm những giá trị biểu đạt theo chiều hướng siêu việt hóa khi đòi hỏi một tư duy phi lý tính để chấp nhận những vấn đề mới trong đời sống xã hội. Đó là "một hình thức hiện đại hóa các huyền thoại, đem nó lại gần hơn với thế giới hiện tại bằng cách mở rộng cách hiểu và cách sử dụng của nó" (Lê Ngọc Thúy và Trần Thị Nâu, 2014, tr 178). Trong Hóa thân, Samsa làm việc tất bật như một cỗ máy để tìm về khoản thu nhập cho gia đình, cung phụng nhu cầu của cha mẹ và em gái, trong khi họ xem việc kiếm tiền của anh là nghĩa vụ đương nhiên. Khi các giá trị mang on - trả ơn giữa Samsa và các thành viên trong gia đình dần phai nhạt thì biên độ giữa ý thức và vô thức cũng bị xóa nhòa. Trong hình hài con bọ, Samsa nhận ra được giá trị của bản thân, giá trị của một cỗ máy kiếm tiền đối với gia đình của mình. Sự bừng tỉnh của anh là quá muộn để bản thân có thể tự chủ về hành động khi lốt bọ đang dần tước bỏ phần người trong bản thân Samsa. Như vậy, sự tỉnh thức triết học cùng các song đề "Vật hóa/ tha hóa; Vật hóa/ bừng ngộ và Bừng ngộ/ giải thoát" (Đặng Anh Đào, 1997, tr 648) như là một phản đề có khả năng làm sáng tỏ sự vô thức trong hành động của nhân vật.

Trong kỷ nguyên kỹ trị, con người từ vị thế chủ nhân sáng tạo các giá trị vật chất để phục vụ cho bản thân mình, bỗng chốc biến thành nô lệ, đánh mất hình hài bên ngoài lẫn nhân tính bên trong: "Mọi người dần quen với điều này một cách đương nhiên, cả gia đình lẫn chính bản thân Gregor. Những đồng tiền được đón nhận với lòng biết ơn và được ban phát với niềm vui sướng, nhưng nào còn nữa cái tình cảm nồng nhiệt đặc biệt trào dâng như hồi đầu" (Kafka, 2018, tr 61). Để đánh đổi lại những giá trị vật chất hằng ao ước, Gregor Samsa phải “....chạy rông hết ngày này sang ngày khác. Một công việc thật còn khó chịu hơn cả chuyện bán buôn ở cửa hàng và bực mình nhất đời là cứ phải liên tục di chuyển, cứ phải lo lắng chuyển đổi tàu, chuyển ga, ăn uống thất thường, gặp đâu ngủ đấy, lúc nào cũng phải làm quen với những kẻ tình cờ gặp gỡ để rồi không bao giờ thấy mặt lần thứ hai, không bao giờ trở thành bạn hữu thân tình" (Kafka, 2018, tr 12). Suy cho cùng, thứ cùm gông trói buộc Samsa và các thành viên trong gia đình anh không gì khác ngoài những ham muốn vật chất mà chính bản thân họ ao ước có được. Từ một con người có hình hài bình thường, chỉ trong phút chốc, anh biến đổi thành một con bọ: "Anh nằm ngửa trên cái lưng rắn như thể được bọc giáp sắt, và khi dợm nhấc đầu lên, anh nhìn thấy bụng mình khum tròn, nâu bóng, phân chia thành nhiều đốt cong cứng đờ; tấm chăn bông đắp trên bụng đã bị xô lệch, gần tuột hẳn. Chân anh nhiều ra, mảnh khảnh đến thảm hại so với phần còn lại của một thân hình to đùng, vung vẩy bất lực trước mắt anh" (Kafka, 2018, tr 9). Điều Kafka muốn nhấn mạnh, trong xã hội hiện đại, bất cứ ai cũng có thể bị biến dạng, cả về hình hài bên ngoài lẫn tính cách bên trong, nếu không làm chủ được chính mình. Rõ ràng, Kafka khéo léo đan cài "cái thường nhật" và "cái quái đản” (Đặng Anh Đào, 1997, tr 650) trong tác phẩm. Cái quái đản (sự biến đổi ngoại diện) có tác dụng gợi vấn đề kì dị của Gregor Samsa ở đầu tác phẩm thì cái thường nhật có tác dụng giải thích cho sự biến đổi ây, dù là cách giải thích mơ hồ qua cơ chế kì dị: "những giấc mơ xáo động" (Kafka, 2018, tr 9). Đặng Anh Đào (1997, tr 650) nhận định: "Sự đan cài quái đản với cái thường nhật khiến từ tác phẩm người ta suy diễn ra một ý nghĩa tư tưởng nữa: cái phi lí đã trở thành cái bình thường hằng ngày”.

\subsection{Các yếu tố hỗ trợ trong việc xây dựng motif hóa thân}

Yếu tố "giải thiêng" đóng vai trò quan trọng trong việc xây dựng motif hóa thân. Nếu yếu tố "thiêng" trong huyền thoại là vấn đề căn cốt để thể hiện những niềm tin, khát khao, mong ước của con người đối với đời sống thì "giải thiêng" trong motif phản huyền thoại là yếu tố để thể hiện cảm quan bi đát của con người khi cuộc sống khi mọi thứ dần trở nên méo mó và biến chuyển khôn lường. Trong Hóa thân, đó là "sự tan vỡ về hình tượng con người về khả năng tồn tại, khả năng tự khẳng định chính mình, và nhất là khả năng bảo vệ được nhân tính, là giá trị cao nhất của con người” (Lê Ngọc Thúy và Trần Thị Nâu, 2014, tr 194) hay thậm chí tạo nên sự đối sánh bất cân xứng giữa "cảm quan về sự hèn mọn nhỏ bé" (Lê Ngọc Thúy và Trần Thị Nâu, 2014, tr 194) với giá trị bản thể của con người. Chủ thể của hoạt động biến đổi chỉ là một anh nhân viên chào 
hàng của một hãng vải, Samsa chẳng phải thần linh, thượng đế hay bất cứ một thế lực siêu nhiên nào nhưng anh ta vẫn có thể tự thân biến đổi như cách mà các vị thần đã làm. Tuy nhiên, khác với vẻ đẹp uy dũng của các vị thần trong thần thoại (những lần hóa thân của nhân vật Zeus trong Thần thoại Hy Lạp là một ví dụ), Samsa chỉ là một kiếp người nhỏ bé với số phận mong manh, bi đát. Thứ mà anh ta biến đổi là hình hài một con bọ khổng lồ, xấu xí nhưng lại có khuôn mặt, ý nghĩ và hành động của con người. Các chi tiết miêu tả được sử dụng đậm đặc là một phương thức đắc lực để nhà văn lột tả về ngoại diện của nhân vật. Bên cạnh đó, tính siêu nhiên, dị thường mà motif hóa thân thể hiện ở các thể loại mang dáng dấp huyền thoại cũng bị phá vỡ một cách triệt để mà thay vào đó là nghệ thuật phục dựng cái phi lý dẫn dắt độc giả tiếp nhận như một sự thật hiển nhiên. Samsa chết là điều tất yếu bởi nhân vật đã đánh mất chính mình. Yếu tố giải thiêng là cơ sở phô bày sự đổ vỡ niềm tin của con người trong xã hội hiện đại, điều này "giống như một phản ứng đối với căn bệnh tôn thờ vật chất và vật chất hóa các giá trị”" (Lê Ngọc Thúy và Trần Thị Nâu, 2014, tr 181).

Sử dụng chi tiết "giấc mơ" là kĩ thuật khá quen thuộc trong các sáng tác của Kafka. Sự biến đổi quái dị về hình hài của nhân vật không hề có bất kì một lời giải thích cụ thể nào mà chỉ được mô tả một cách ngắn gọn ngay từ đầu tác phẩm: "Một sáng tỉnh giấc sau những giấc mơ xáo động, Gregor Samsa, nằm trên giường, nhận thấy mình đã biến thành một con côn trùng khổng lồ" (Kafka, 2018, tr 9). Chi tiết "giấc mơ" trong Hóa thân có nét tương đồng với chi tiết "giấc mơ" trong truyện ngắn Samsa yêu của Hakuri Muramaki. Với truyện ngắn Samsa yêu (Haruki Murakami), nhân vật anh dùng đời sống tinh thần để chế ngự nỗi bất hạnh vật chất và có thể chấp nhập thực tại ấy, còn trong Hóa thân (Franz Kafka), Samsa phải "khép mình lại trong "cái mình có", cho dù "cái mình có" đó chỉ là hoàn toàn về mặt tinh thần, tư duy không mấy chắc chắn này là một cách chống đỡ tạm thời trước cuộc sống" (Lộc Phương Thủy, 2017, tr 313). Giấc mơ được xây dựng như một yếu tố huyễn ảo mang hàm ý nhắc đến những tác động của bối cảnh xã hội mà nhân vật đang tồn tại. "Trong những giấc mơ mang tính bản thể này, Kafka đã chạm đến được nhiều bí ẩn trong đời sống tâm hồn con người" (Lê Huy Bắc, 2013, tr 56). Song hành cùng một âm thanh trong trẻo về cái kết có hậu được đặt ra ở đoạn kết tác phẩm, Kafka mang đến cho độc giả cái nhìn bi đát về số phận con người với “cảm hứng mỉa mai" (Lê Huy Bắc, 2019, tr 16) đầy chua xót trong đời sống hiện đại.
Kafka sinh trưởng trong một thời kỳ đầy biến động, phong trào đàn áp người Do Thái, chiến tranh thế giới ở thế kỷ XX,... đã tạo lên một cảm quan đổ vỡ, hoài nghi về các giá trị trong đời sống hiện đại. Những đớn đau trong cuộc đời đã dựng nên cảm quan hư vô trong suy tưởng của Kafka. Điều này làm ông hoài nghi vào thực tại, cảm thấy cuộc sống con người hư vô và trống rỗng. Rõ ràng, thế giới mà ông đang sống là thế giới mơ hồ, hỗn độn, vô nghĩa và bất khả nhận thức. Kafka đề cập đến con người cá nhân, con người bản thể nhưng không phải con người với bản thể nguyên vẹn, mà là con người với bản thể "vỡ tan thành nhiều mảnh" (Lê Huy Bắc, 2013, tr 16). Diễn trình hóa thân của nhân vật được kể từ một sáng nọ, sau một giấc mơ nhân vật hóa thành con vật, và cuối cùng nhân vật đi đến sự diệt vong - cái chết. Câu chuyện kể về Samsa vốn không hoàn chỉnh, tròn vẹn, mà chỉ là lát cắt, phiến vỡ trong cuộc đời nhân vật. Kafka muốn độc giả cùng suy ngẫm, luận giải về văn bản - nơi chứa đựng vô số những khả thể của sự diễn dịch.

\section{KẾT LUẬN}

Nghiên cứu Hóa thân của Franz Kafka, chúng tôi nhận thấy motif hóa thân đóng vai trò quan trọng trong việc truyền tải các vấn đề "bất khả giải" trong đời sống hiện đại. Motif hóa thân được Kafka vận dụng sáng tạo từ một motif nghệ thuật mang tính huyền thoại trong văn học truyền thống. Diễn trình hóa thân của nhân vật gợi người đọc nhiều suy nghiệm về sự phá sản, đồ vỡ niềm tin và mối nguy đánh mất chính mình trong xã hội hiện đại.

Franz Kafka mang đến cho người đọc một cái nhìn nghiệt ngã về hiện thực và con người trong kỷ nguyên kỹ trị của nhân loại. Con người vẫn tồn tại nhưng bản thể bị phân mảnh thành nhiều phiến đoạn đầy vụn vỡ, lạc lõng và cô đơn. Khi ấy, con người bị "phân tán thành "một chủ thể phi trung tâm", bao hàm nhiều mảnh vụn và tất cả đều bị hòa tan trong bối cảnh xám xịt chung quanh" (Phương Lựu, 2011, tr 56). Hiện thực được tái hiện trong tác phẩm là hiện thực trúc trắc, không tròn vẹn, mà đầy sự hoài nghi và phi lý. Điều này phô bày sự vụn vỡ, trống vắng và không tái sinh trong đời sống con người.

\section{TÀI LIỆU THAM KHẢO}

Đặng Anh Đào (Chủ biên) (2006). Văn học phương Tây. Nhà xuất bản Giáo dục.

Garaudy, R. (2007). Kafka. Trong: Lộc Phương Thủy (Chủ biên). Li luận - phê bình văn học thế giới thể kỷ XX (Tập 1). Nhà xuất bản Giáo dục. Hà Nội, 284 - 325. 
Kafka, F. (2018). Hóa thân (Đức Tài dịch). Nhà xuất bản Hội nhà văn.

La Mai Thi Gia, 2015. Motif nghiên cứu truyện dân gian: lý thuyết và ứng dụng. Nhà xuất bản Văn hóa - văn nghệ. Hồ Chí Minh, 300 trang.

Lại Nguyên Ân (Biên soạn) (2003). 150 thuật ngũu văn học. Nhà xuất bản Đại học Quốc gia Hà Nội.

Lê Huy Bắc, 2013. Văn học hậu hiện đại: lí thuyết và tiếp nhận. Nhà xuất bản Đại học Sư phạm. Hà Nội, 320 trang.

Lê Huy Bắc, 2019. Franz Kafka - Người tẩy não nhân loại. Nhà xuất bản Tổng hợp Thành phố Hồ Chí Minh. Hồ Chí Minh, 319 trang.

Lê Ngọc Thúy và Trần Thị Nâu, 2014. Giáo trình văn học châu Âu. Nhà xuất bản Đại học Cần Thơ. Cần Thơ, 199 trang.
Lê Thanh Nga, 2006. Huyền thoại hóa như một phương thức khái quát hiện thực đặc thù trong các sáng tác của Franz Kafka. Tạp chí Văn học nước ngoài. 4: 172-188.

Nguyễn Lân, 2000. Từ điển từ và ngũ Việt Nam. Nhà xuất bản Thành phố Hồ Chí Minh. Hồ Chí Minh, 2111 trang.

Nguyễn Thị Mai Liên, 2019. Motif folklore trong sáng tác của Franz Kafka và Haruki Muramaki, ngày truy cập 20/9/2020. Địa chỉ

http://nguvan.hnue.edu.vn/Nghiencuu/Vanhocnu ocngoai/tabid/105/newstab/3416/Default.aspx

Phương Lựu, 2011. Lý thuyết văn học hậu hiện đại. Nhà xuất bản Đại học Sư phạm. Hà Nội, 279 trang. 